\title{
BMJ Open How do people perceive different labels for rotator cuff disease? A content analysis of data collected in a randomised controlled experiment
}

To cite: Zadro JR, Michaleff ZA, O'Keeffe M, et al. How do people perceive different labels for rotator cuff disease? A content analysis of data collected in a randomised controlled experiment. BMJ Open 2021;11:e052092. doi:10.1136/ bmjopen-2021-052092

- Prepublication history and additional supplemental material for this paper are available online. To view these files, please visit the journal online (http://dx.doi.org/10.1136/ bmjopen-2021-052092).

Received 06 April 2021 Accepted 17 November 2021

Check for updates

(c) Author(s) (or their employer(s)) 2021. Re-use permitted under CC BY-NC. No commercial re-use. See rights and permissions. Published by BMJ.

For numbered affiliations see end of article.

Correspondence to Joshua R Zadro;

joshua.zadro@sydney.edu.au

\section{ABSTRACT}

Objectives Explore how people perceive different labels for rotator cuff disease in terms of words or feelings evoked by the label and treatments they feel are needed. Setting We performed a content analysis of qualitative data collected in a six-arm, online randomised controlled experiment.

Participants 1308 people with and without shoulder pain read a vignette describing a patient with rotator cuff disease and were randomised to one of six labels: subacromial impingement syndrome, rotator cuff tear, bursitis, rotator-cuff-related shoulder pain, shoulder sprain and episode of shoulder pain.

Primary and secondary outcomes Participants answered two questions (free-text response) about: (1) words or feelings evoked by the label; (2) what treatments they feel are needed. Two researchers iteratively developed coding frameworks to analyse responses.

\section{Results}

1308/1626 (80\%) complete responses for each question were analysed. Psychological distress (21\%), uncertainty (22\%), serious condition (15\%) and poor prognosis $(9 \%)$ were most often expressed by those labelled with subacromial impingement syndrome. For those labelled with a rotator cuff tear, psychological distress (13\%), serious condition (9\%) and poor prognosis (8\%) were relatively common, while minor issue was expressed least often compared with the other labels $(5 \%)$. Treatment/ investigation and surgery were common among those labelled with a rotator cuff tear $(11 \%$ and $19 \%$, respectively) and subacromial impingement syndrome ( $9 \%$ and $10 \%$ ) compared with bursitis ( $7 \%$ and $5 \%)$.

Conclusions Words or feelings evoked by certain labels for rotator cuff disease and perceived treatment needs may explain why some labels drive management preferences towards surgery and imaging more than others.

\section{INTRODUCTION}

Shoulder pain is the third most common musculoskeletal condition seen in primary care. ${ }^{1}$ The 1-year and lifetime prevalence of shoulder pain ranges from $5 \%$ to $47 \%$ and $7 \%$ to $67 \%$, respectively. ${ }^{2}$ Rotator cuff disease, an

\section{Strengths and limitations of the study}

- Our study used a large sample size and a highly reliable coding frameworks ( $\mathrm{k}=0.90-0.97$ across labelling groups for both questions).

- The online experiment which provided data for this study used randomisation and allocation concealment.

- Since this is an online experiment, people's feelings towards different labels and what treatments they feel are needed might be different in a real-life clinical encounter.

- Other labels not investigated in this study (eg, rotator cuff disease, painful arc syndrome) may have provoked different words or feelings and perceived treatment needs.

- We only focused on the feelings and needs of patients and the public, whereas clinician-related factors (eg, beliefs, bias) might be a stronger driver of management choices in real-life

umbrella term that encompasses conditions relating to the rotator cuff and surrounding structures (including rotator cuff tendinopathy and tears, calcific tendinitis and subacromial bursitis) accounts for $85 \%$ of cases of shoulder pain. ${ }^{3}$ Other causes of shoulder pain include adhesive capsulitis, glenohumeral osteoarthritis, fracture, dislocation and instability, malignancy and referred pain from visceral causes. ${ }^{4}$

Neither clinical features nor diagnostic imaging can reliably pinpoint a specific nociceptive cause of rotator cuff disease from the numerous candidate pain-sensitive structures in the shoulder (eg, tendon, bursa). ${ }^{5-11}$ Possibly as a result of such uncertainty, there are a plethora of diagnostic labels that have been used in both routine practice and research to indicate the same condition. ${ }^{12}$ Some labels describe the clinical features (eg, painful arc syndrome), the 
purported or observed pathology (eg, rotator cuff tear), or the presumed aetiology (eg, subacromial impingement syndrome).

Different labels for the same condition can influence people's management preferences, psychological outcomes and perceptions of condition severity. ${ }^{13}$ For example, we recently conducted a large online randomised controlled experiment in people with and without shoulder pain $(n=1308)$ to explore whether different labels for rotator cuff disease influence people's management preferences. People told they had a rotator cuff tear had higher perceived need for both surgery and imaging compared with those told they had bursitis, and those told they had subacromial impingement syndrome had higher perceived need for imaging compared with those told they had bursitis. ${ }^{14}$

Shoulder surgeries such as subacromial decompression and rotator cuff repair ${ }^{15-20}$ are frequently performed for patients with rotator cuff disease, ${ }^{15-18}$ but current evidence indicates these procedures are not superior to placebo or non-operative management. ${ }^{19}{ }^{20}$ Diagnostic imaging is also unnecessary for most patients with rotator cuff disease because it cannot reliably identify a specific nociceptive cause of rotator cuff disease, it does not inform management decisions, and can encourage use of surgery by identifying 'incidentalomas'. ${ }^{7-11}$ Despite this, clinicians frequently order imaging. ${ }^{21} 22$ Our trial identified labels for rotator cuff disease that reduce people's perceived need for shoulder surgery and imaging. These findings could be an important starting point for reducing unnecessary healthcare for shoulder pain.

As part of our online randomised controlled experiment, ${ }^{14}$ we collected qualitative data that could help to uncover why preferences differed based on the diagnostic label people received. The aim of this study was to explore how people with and without shoulder pain in our online experiment perceived different labels for rotator cuff disease in terms of words or feelings evoked by the label and treatments they feel are needed.

\section{MATERIALS AND METHODS}

\section{Study design}

We performed a content analysis of qualitative data collected in a six-arm, online randomised controlled experiment in participants with and without shoulder pain. ${ }^{14}$

\section{Participants and recruitment}

Participants aged 18-65 years old from Australia, New Zealand, USA, UK and Canada were recruited through Qualtrics (www.qualtrics.com) between April and June 2020. Qualtrics is a market research company that recruits using existing, nationally representative panels of individuals who have previously agreed to complete surveys. Qualtrics employs random sampling and provides incentives for participants to complete surveys (eg, cash, airline miles, gift cards). Details on the sampling and recruitment procedures Qualtrics use are reported elsewhere. ${ }^{14} 23$ Qualtrics recruited three groups of participants (evenly distributed) for our study: those who had never experienced shoulder pain, those who had shoulder pain at the time of participation and those who had previously experienced shoulder pain but were pain-free at the time of participation.

\section{Data collection}

Participants provided data on demographics, and if applicable, healthcare utilisation and shoulder symptoms. This included data on age, gender, educational attainment, country of residence, employment status, private health insurance status, symptoms of anxiety and depression, history of shoulder pain, history of diagnostic imaging for shoulder pain (X-ray, ultrasound, MRI), history of injections for shoulder pain, history of shoulder surgery, history of sick leave due to shoulder pain, history of receiving a diagnosis for shoulder pain, duration of current shoulder pain and Shoulder Pain and Disability Index (SPADI) scores. Details on how these data were collected are reported elsewhere. ${ }^{14}$

Participants read a vignette describing a patient with rotator cuff disease and were randomised to one of six labels. Randomisation was not stratified by the three groups of participants with different experiences of shoulder pain. Each label was accompanied by a brief explanation of the label:

- 'Subacromial impingement syndrome. Subacromial impingement syndrome describes shoulder pain caused by compression of soft tissue (eg, tendons, bursa) from bony parts of the shoulder'.

- 'Rotator cuff tear. A rotator cuff tear is a tear in one of the shoulder tendons'.

- 'Bursitis. Bursitis is inflammation of a fluid-filled sac called a bursa in the shoulder'.

- 'Rotator-cuff-related shoulder pain. Rotator-cuffrelated shoulder pain describes shoulder pain caused by an injury to one of the shoulder tendons'.

- 'Shoulder sprain. Shoulder sprain describes shoulder pain caused by a sprain of either muscles, ligaments and/or tendons that support the shoulder'.

- 'Episode of shoulder pain' (control label; no explanation provided).

In the vignette, the health professional described all labels as non-serious and likely to resolve over time (box 1).

Outcome data were collected immediately after participants were randomised to a label. In this paper, we focus on free-text responses to two questions:

1. When you hear the term (one of the six labels), what words or feelings does this make you think of? Please list.

2. What treatment(s) (if any) do you think a person with a (one of the six labels) needs? Please list.

\section{Data analysis}

Free-text responses to the above questions were analysed using content analysis. Content analysis combines 


\section{Box 1 Vignette}

\section{You have shoulder pain}

This next section describes a person with shoulder pain who goes to a healthcare provider.

We want you to put yourself into this scenario, and do your best to imagine that you are the person having this shoulder pain.

After reading it, you will be asked a number of questions. Please do your best to answer them based on this imagined scenario.

Your shoulder pain

- Imagine you are suffering from pain in your right shoulder.

- It started 2 months ago.

- There was no specific incident/injury/trauma that caused your pain.

- You think the pain was triggered by reaching for a plate in a high cupboard, but you are not sure.

- You have no pain or other unusual sensations past your shoulder (eg, pins and needles, numbness).

- The pain is at the front, side and back of your right shoulder and right upper arm, as shown by the red circles on the picture of the body chart below.

- You find it hard to move your shoulder normally. In particular, you find it very hard to lift your right arm past horizontal ('eye level') and reach up to high cupboards.

- You cannot lie on your right side in bed as this increases your pain.

- You have used heat and over the counter pain relievers, and have been avoiding using your right shoulder to reach for objects or carry heavy shopping.

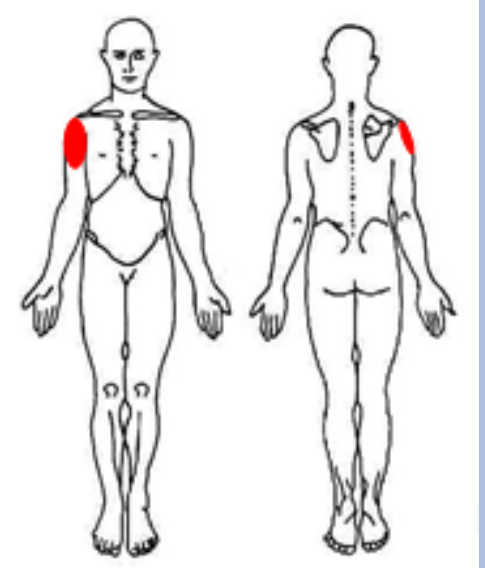

You visit a healthcare provider (eg, general practitioner or physiotherapist)

Your healthcare provider asks you questions about your shoulder pain, and some health questions to rule out any worrying causes.

Your healthcare provider does a detailed physical examination. It involves:

- Looking at your shoulder.

- Checking if you can move your shoulder in certain directions, and whether this causes pain.

- Checking if they can move your shoulder in certain directions, and whether this causes pain.

- Checking if movement of your shoulder against resistance causes pain.

After this, your healthcare provider tells you:

'You have (label)'

'I am not worried that there is anything serious going on here because your pain is not related to severe trauma. I am also not worried that

Continued

\section{Box 1 Continued}

you have arthritis in your shoulder or a specific condition called frozen shoulder that causes severe pain and stiffness. Your pain should gradually improve over time by itself. It is recommended that you temporarily avoid activities that aggravate your pain and continue to use your arm so your shoulder does not stiffen up'.

This vignette was originally published in the Journal of Orthopaedic \& Sports Physical Therapy. ${ }^{14}$ They own the copyright to this material.

quantitative and qualitative research methods and is a well-accepted approach for analysing text data. ${ }^{24}$ Content analysis allowed us to report the frequency of themes expressed in responses. Two researchers with experience in qualitative research and a physiotherapy background (JZ and ZAM) initially read through the responses to become familiar with their content. As such, the analysis represents the perspectives of physiotherapists currently working in research and with extensive experience managing patients with musculoskeletal pain. To develop the coding frameworks (one for each question), an inductive approach embedded in grounded theory was used. The two researchers independently coded 50 responses from each labelling group for both questions ( $24 \%$ of all responses). The frameworks were then compared, discussed and harmonised into one framework for each question for the next stage of coding.

Once the frameworks had been developed, the two researchers independently applied the frameworks to a random sample of responses, ensuring at least $20 \%$ of responses from each labelling group were coded. Each response was allocated as many codes as appropriate; nine was the highest number of codes given to a single response. The development and use of the frameworks occurred between July and August 2020. Kappa statistics (k) and 95\% CI and exact agreement $(\%)$ were calculated to assess the level of agreement between JZ and ZAM for coding responses to both questions. $\mathrm{k}$ values were interpreted as: $\angle 0.00=$ "poor', $0.00-0.20=$ 'slight', $0.21-$ $0.40=$ "fair', $\quad 0.41-0.60=$ ='moderate', $0.61-0.80=$ 'substantial' and $\geq 0.81=$ 'almost perfect'. ${ }^{25}$ Analyses investigating level of agreement were performed using Stata (V.16.1) and 5000 bootstrap replications were used to calculate $95 \%$ CI. Reliability of the coding framework was deemed acceptable if level of agreement between the two researchers coding a random sample of responses was $\mathrm{k} \geq 0.8$. Once agreement was acceptable, the two researchers (JZ and ZAM) applied the framework to the remaining responses. A detailed outline of the final coding frameworks is presented in online supplemental table 1 .

\section{Patient or public involvement}

Patients and members of the public were not involved in the design of this study nor were they involved in the validation of the data. 


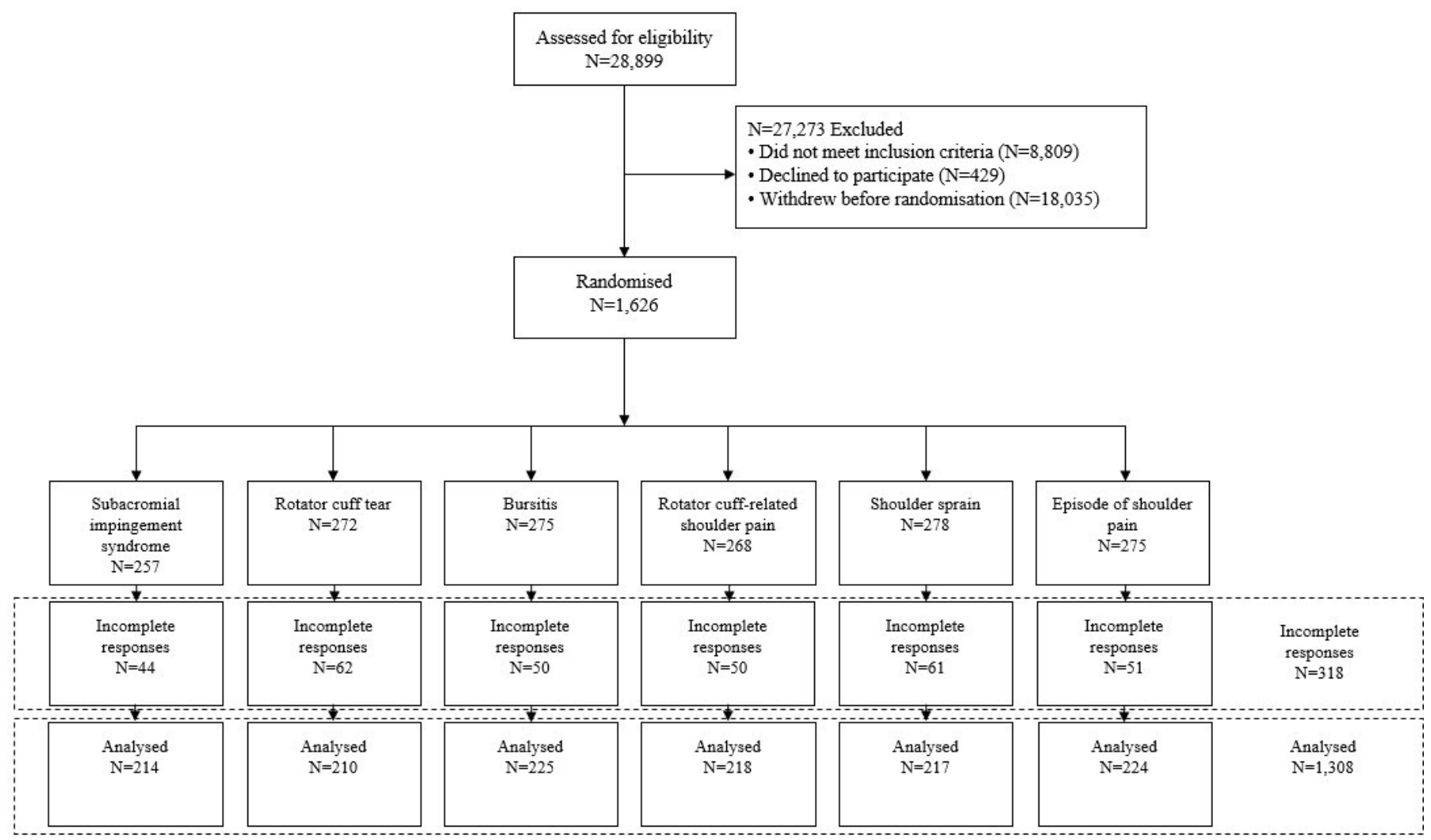

Figure 1 Flow diagram.

\section{RESULTS}

\section{Sample characteristics and level of agreement}

In our online trial, 1626 eligible participants were randomised to the six labelling arms (figure 1); 318 participants $(19.6 \%)$ did not respond to the free-text response questions, leaving 1308 (80.4\%) responses to each question for inclusion in the analysis (2618 total responses). Level of agreement between the two researchers coding a random sample of responses was 'almost perfect' for question 1 (range across the six labelling groups: $\mathrm{k}=0.90$ 0.97 ) and question $2(\mathrm{k}=0.91-0.97)$ (online supplemental table 2).

Characteristics of the sample are reported in table 1 . In summary, there were $437(33.4 \%)$ participants with no history of shoulder pain, $434(33.2 \%)$ currently experiencing shoulder pain and $437(33.4 \%)$ with a history of shoulder pain but currently pain free. Participants' mean age (SD) was $40.3(16.0)$ years and $59.1 \%$ were females. For participants with previous or current shoulder pain, $65.6 \%$ had received treatment for their shoulder pain and $27.7 \%$ had been given a specific diagnosis, $44.4 \%$ had received imaging, $21.2 \%$ an injection and $8.7 \%$ surgery for their shoulder pain. Characteristics were largely similar between the six labelling groups.

When you hear the term (one of the six labels), what words or feelings does this make you think of?

Our framework included 15 themes (table 2). Online supplemental table 3 provides examples of participants' free-text responses for this question. Pain experience was the most common theme across all labelling groups (30.8\%-59.4\% of responses). Activity restriction was most often expressed by participants labelled with a shoulder sprain $(25.8 \%)$, rotator-cuff-related shoulder pain $(21.1 \%)$ and episode of shoulder pain (18.3\%). Tissue damage or dysfunction was most often expressed by participants labelled with bursitis (36.0\%), rotator cuff tear $(21.9 \%)$ and shoulder spain (20.7\%).

Uncertainty was most often expressed by participants labelled with subacromial impingement syndrome (22.0\%) and bursitis (13.3\%), and least often expressed by those labelled with a rotator cuff tear $(4.8 \%)$ and shoulder sprain $(0.9 \%)$. Psychological distress $(20.6 \%)$ and serious issue (15.4\%) were most often expressed by participants labelled with subacromial impingement syndrome; serious issue was least often expressed by those labelled with bursitis $(2.7 \%)$, rotator-cuff-related shoulder pain (4.1\%), shoulder sprain (2.3\%) and episode of shoulder pain (0.9\%) (table 2).

Good prognosis was most often expressed by participants labelled with an episode of shoulder pain (17.4\%) and shoulder sprain $(16.6 \%)$, and least often expressed by those labelled with subacromial impingement syndrome (4.7\%) and rotator-cuff-related shoulder pain (4.1\%). Poor prognosis was most often expressed by participants labelled with subacromial impingement syndrome (9.3\%) and rotator cuff tear $(8.1 \%)$, and least often expressed by those labelled with bursitis (2.7\%) and episode of shoulder pain $(3.1 \%)$. Treatment/investigation was most often 


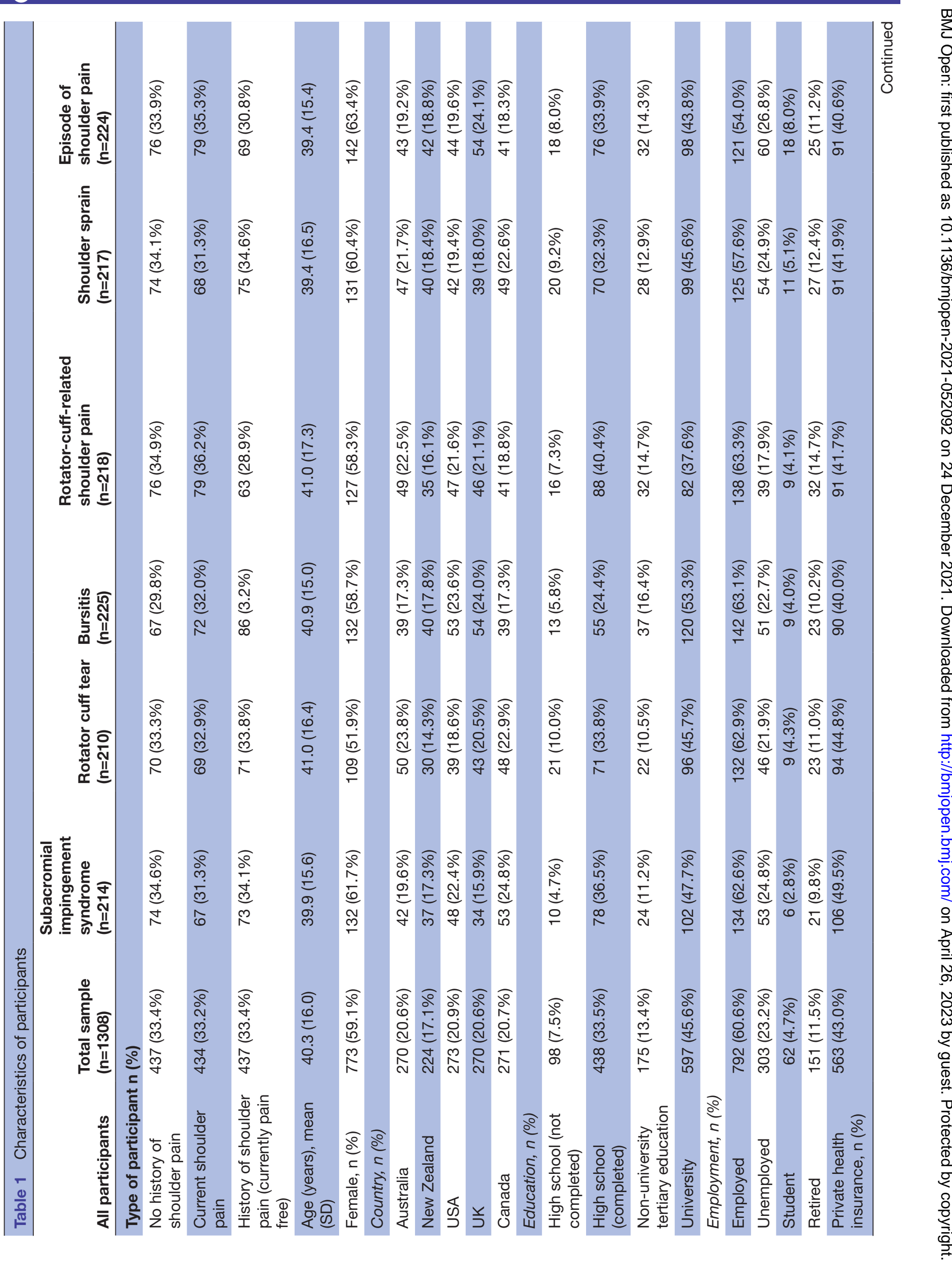




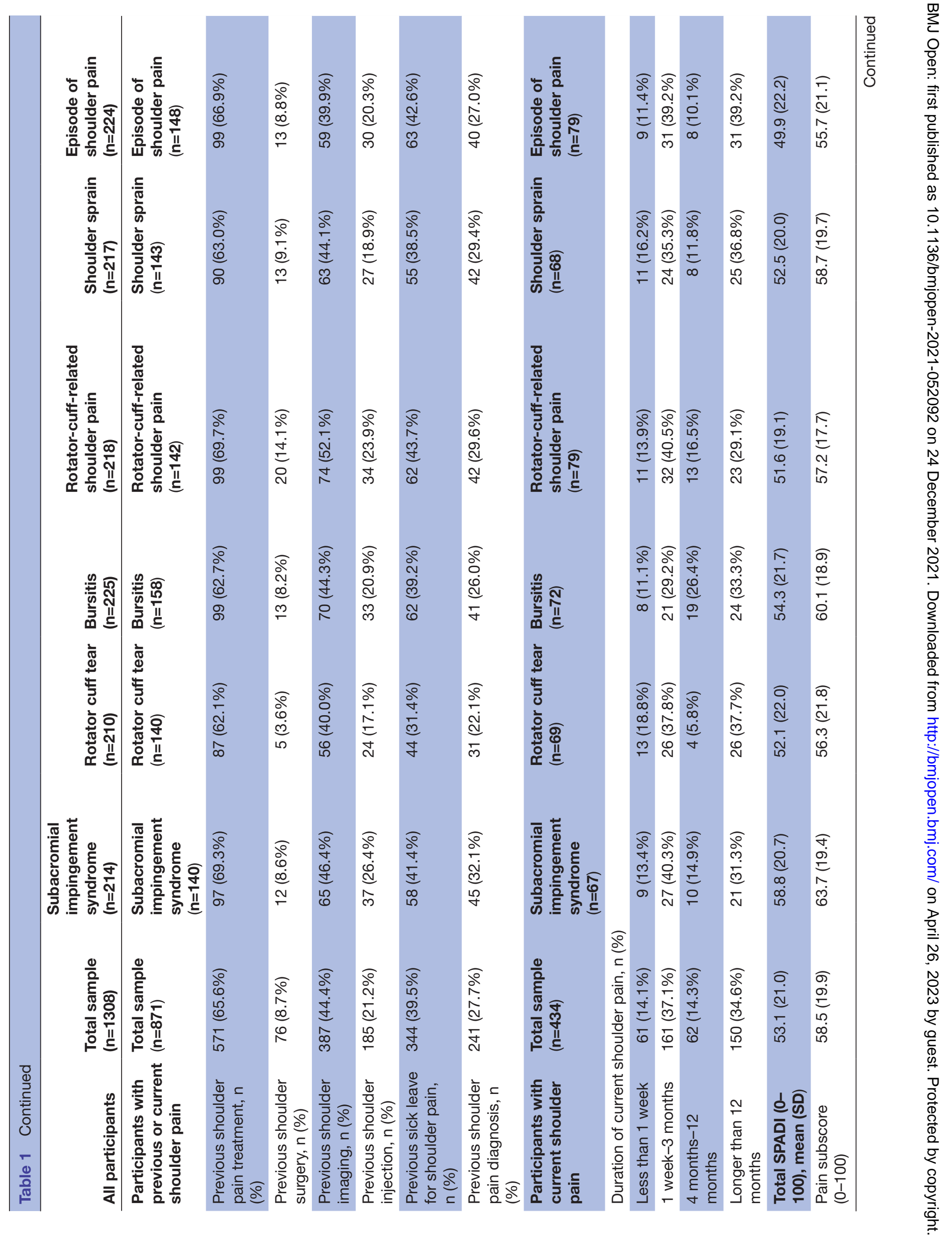


expressed by participants labelled with a rotator cuff tear $(11.0 \%)$ and rotator-cuff-related shoulder pain (9.6\%). Minor issue was most often expressed by participants labelled with a shoulder sprain (12.9\%), and least often expressed by those labelled with a rotator cuff tear $(4.8 \%)$ (table 2 ).

\section{What treatment(s) (if any) do you think a person with (one of the six labels) needs?}

Our framework included 41 themes. The most common treatment themes expressed across the labels were medication $(17.1 \%-37.1 \%$ of responses), rest $(15.6 \%-$ $28.0 \%)$, physiotherapy $(13.3 \%-25.0 \%)$ and exercise $(11.7 \%-19.8 \%)$. Surgery was most often expressed by participants labelled with a rotator cuff tear $(19.0 \%)$ and rotator-cuff-related shoulder pain (18.3\%), and least often expressed by those labelled with bursitis (4.9\%) and episode of shoulder pain (5.8\%). Injection was most often expressed by participants labelled with subacromial impingement syndrome (11.7\%), bursitis (9.8\%) and episode of shoulder pain $(9.4 \%)$, and least often expressed by those labelled with a rotator cuff tear (5.7\%). Investigation was most often expressed by participants labelled with an episode of shoulder pain (8.9\%) and rotator-cuff-related shoulder pain (7.3\%), and was expressed by $3.1 \%-4.6 \%$ of participants across the other labels (tables 3 and 4; online supplemental table 4).

\section{DISCUSSION \\ Summary of key findings}

There was a variety of themes elicited from the two questions regarding words or feelings evoked by the diagnostic label and treatments perceived as necessary for rotator cuff disease. The findings could explain why, in the quantitative part of our trial, ${ }^{14}$ participants labelled with subacromial impingement syndrome had higher perceived need for imaging when compared with those labelled with bursitis, and those labelled with a rotator cuff tear had higher perceived need for surgery and imaging when compared with those labelled with bursitis. Feelings of psychological distress, uncertainty and that the condition is serious and has a poor prognosis were commonly expressed by those labelled with subacromial impingement syndrome. For those labelled with a rotator cuff tear, feelings of psychological distress, and that the condition is serious and has a poor prognosis were relatively common, while few perceived it as a minor issue. Although feelings of tissue damage or dysfunction were expressed most often by participants labelled with bursitis, it was uncommon for participants to perceive bursitis as a serious condition, a condition with a poor prognosis or a condition associated with psychological distress. These themes might explain why the need for treatment/investigation and surgery were more common among those labelled with a rotator cuff tear and subacromial impingement syndrome compared with bursitis. 


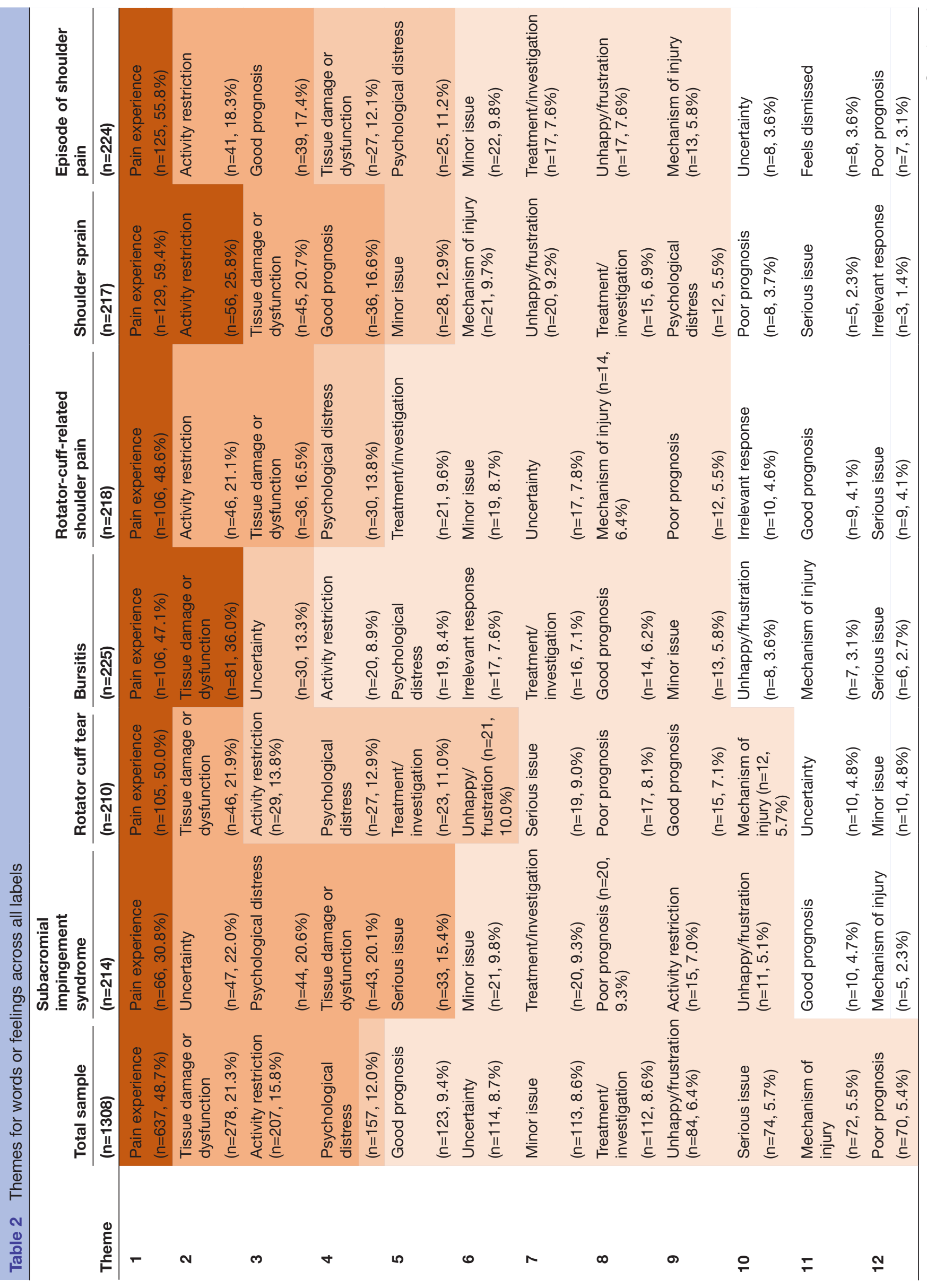




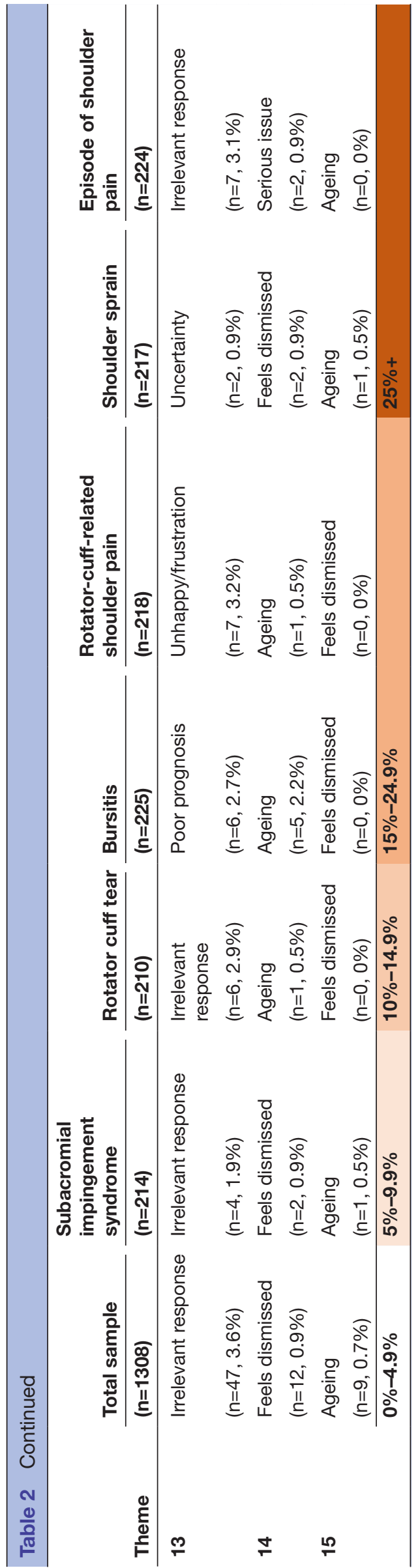

\section{Strengths and weaknesses of this study}

Key strengths of this study include use of a large sample size, highly reliable coding frameworks $(\mathrm{k}=0.90-0.97$ across labelling groups for both questions) and including people with and without shoulder pain. Including people with and without the target health condition is important when trying to explore the perceptions of both patients and the general public, yet it is uncommon in labelling studies. ${ }^{13}{ }^{26-29}$ Another strength is that the online experiment which provided data for this study used high-quality methods (eg, randomisation, allocation concealment).

The main weakness of this study is that it was an online experiment; hence, people's feelings towards different labels and what treatments they feel are needed might be different in a clinical encounter. Other labels not investigated in this study (eg, rotator cuff disease, painful arc syndrome) may have provoked different words or feelings and perceived treatment needs. We were missing data from 318 participants who were randomised but did not complete outcome measures. However, our sample appears representative of people presenting with shoulder pain in primary care in terms of demographics, healthcare utilisation and shoulder pain and function. ${ }^{330-33}$ Outcomes were only assessed immediately after participants were given the label. Our findings may have been different if we gave participants more time to reflect on their label. Since the health professional in the vignette was not concerned about any label, participants may have had fewer negative feelings towards the labels and felt extensive treatment was unnecessary. Very low health literacy may have also limited understanding of the message from the health professional in the vignette. The need for investigation may have been low in response to the second question $(3.1 \%-8.9 \%)$ because the question only referred to what 'treatments' a person needs. This study only focused on the feelings and needs of patients and the public, whereas clinician-related factors (eg, beliefs, bias) might be a stronger driver of management choices in the real world. Finally, since two researchers, both with a physiotherapy background developed and applied the coding frameworks, it is possible professional bias and beliefs may have influenced the coding.

\section{Meaning of the study}

The qualitative findings from our online randomised controlled experiment (ie, the current content analysis) corroborate with the quantitative findings ${ }^{14}$ and highlight the potential value of avoiding certain labels for rotator cuff disease. Our online experiment found participants labelled with a rotator cuff tear had higher perceived need for surgery and imaging when compared with those labelled with bursitis, while those labelled with subacromial impingement syndrome had higher perceived need for imaging when compared with those labelled with bursitis. In this content analysis, participants labelled with subacromial impingement syndrome and rotator cuff tear were more likely to associate these labels with psychological distress, a serious condition, poor prognosis and the need for 
Table 3 Top 10 treatment themes for each label

\begin{tabular}{|c|c|c|c|c|c|c|}
\hline Theme & $\begin{array}{l}\text { Subacromial } \\
\text { impingement } \\
\text { syndrome } \\
(n=214)\end{array}$ & $\begin{array}{l}\text { Rotator cuff } \\
\text { tear }(n=210)\end{array}$ & Bursitis ( $n=225)$ & $\begin{array}{l}\text { Rotator-cuff-related } \\
\text { shoulder pain }(n=218)\end{array}$ & $\begin{array}{l}\text { Shoulder sprain } \\
(n=217)\end{array}$ & $\begin{array}{l}\text { Episode of } \\
\text { shoulder pain } \\
(n=224)\end{array}$ \\
\hline 1 & $\begin{array}{l}\text { Rest }(n=59 \text {, } \\
27.6 \%)\end{array}$ & $\begin{array}{l}\text { Physiotherapy } \\
(n=49,23.3 \%)\end{array}$ & $\begin{array}{l}\text { Medication } \\
(n=69,30.7 \%)\end{array}$ & $\begin{array}{l}\text { Medication } \\
(\mathrm{n}=61,28.0 \%)\end{array}$ & $\begin{array}{l}\text { Medication } \\
(n=71,32.7 \%)\end{array}$ & $\begin{array}{l}\text { Medication } \\
(n=83,37.1 \%)\end{array}$ \\
\hline 2 & $\begin{array}{l}\text { Physiotherapy } \\
(n=51,23.8 \%)\end{array}$ & $\begin{array}{l}\text { Rest } \\
(n=47,22.4 \%)\end{array}$ & $\begin{array}{l}\text { Rest } \\
(n=63,28.0 \%)\end{array}$ & $\begin{array}{l}\text { Physiotherapy }(n=52 \text {, } \\
23.9 \%)\end{array}$ & $\begin{array}{l}\text { Rest }(n=55 \\
25.3 \%)\end{array}$ & $\begin{array}{l}\text { Physiotherapy } \\
(n=56,25.0 \%)\end{array}$ \\
\hline 4 & $\begin{array}{l}\text { Activity } \\
\text { modification } \\
(n=38,17.8 \%)\end{array}$ & $\begin{array}{l}\text { Medication } \\
(n=36,17.1 \%)\end{array}$ & $\begin{array}{l}\text { Exercise }(n=31 \\
13.8 \%)\end{array}$ & $\begin{array}{l}\text { Exercise } \\
(n=34,15.6 \%)\end{array}$ & $\begin{array}{l}\text { Exercise } \\
(n=43,19.8 \%)\end{array}$ & $\begin{array}{l}\text { Exercise } \\
(n=34,15.2 \%)\end{array}$ \\
\hline 6 & $\begin{array}{l}\text { Exercise } \\
(n=25,11.7 \%)\end{array}$ & $\begin{array}{l}\text { Exercise } \\
(n=26,12.4 \%)\end{array}$ & $\begin{array}{l}\text { Injection } \\
(n=22,9.8 \%)\end{array}$ & $\begin{array}{l}\text { Exercise (intensity not } \\
\text { specified) } \\
(n=25,11.5 \%)\end{array}$ & $\begin{array}{l}\text { Exercise } \\
\text { (intensity not } \\
\text { specified) } \\
(n=32,14.7 \%)\end{array}$ & $\begin{array}{l}\text { Massage } \\
(n=22,9.8 \%)\end{array}$ \\
\hline 7 & $\begin{array}{l}\text { Surgery } \\
(n=21,9.8 \%)\end{array}$ & $\begin{array}{l}\text { Heat } \\
(n=16,7.6 \%)\end{array}$ & $\begin{array}{l}\text { Heat } \\
(n=20,8.9 \%)\end{array}$ & $\begin{array}{l}\text { Activity modification } \\
(n=19,8.7 \%)\end{array}$ & $\begin{array}{l}\text { Cold } \\
(n=25,11.5 \%)\end{array}$ & $\begin{array}{l}\text { Injection } \\
(n=21,9.4 \%)\end{array}$ \\
\hline 8 & $\begin{array}{l}\text { Exercise } \\
\text { (intensity not } \\
\text { specified) } \\
(n=19,8.9 \%)\end{array}$ & $\begin{array}{l}\text { Unsure } \\
(n=16,7.6 \%)\end{array}$ & $\begin{array}{l}\text { Cold } \\
(n=18,8.0 \%)\end{array}$ & $\begin{array}{l}\text { Injection } \\
(n=16,7.3 \%)\end{array}$ & $\begin{array}{l}\text { Activity } \\
\text { modification } \\
(n=20,9.2 \%)\end{array}$ & $\begin{array}{l}\text { Investigations } \\
(n=20,8.9 \%)\end{array}$ \\
\hline 10 & $0-9.9 \%$ & $10-14.9 \%$ & $15-24.9 \%$ & $25 \%+$ & $\begin{array}{l}\text { Surgery } \\
(n=16,7.4 \%)\end{array}$ & $\begin{array}{l}\text { Activity } \\
\text { modification } \\
(n=18,8.0 \%)\end{array}$ \\
\hline
\end{tabular}

treatment/investigation and surgery, compared with those labelled with bursitis.

Encouraging clinicians to avoid labels that increase patients' perceived need for unnecessary care, such as shoulder surgery and diagnostic imaging, could improve the management of patients with rotator cuff disease. However, since there are no data on the acceptability of avoiding certain labels among patients and health professionals, educating clinicians on the importance of addressing misconceptions among patients with rotator cuff disease may be a more acceptable starting point. For example, patients labelled with subacromial impingement syndrome may need reassurance that they do not have a serious condition and education to reduce any psychological distress or uncertainty. Similarly, patients labelled with a rotator cuff tear may need reassurance that tears rarely need to be repaired because they are common in asymptomatic people and symptoms associated with tears often improve without surgery.

\section{Comparison to existing literature}

Although this is the first study to examine public and patient perceptions of different labels for rotator cuff disease, the findings align with qualitative work which suggests patients given a structural diagnosis (eg, subacromial impingement syndrome, where pain is caused by a bone spur that is reducing the subacromial space) believe surgery will fix their problem. ${ }^{34}$ We found perceived need for treatment/investigation was most common among those labelled with a rotator cuff tear $(11.0 \%)$ and subacromial impingement syndrome $(9.3 \%)$. Furthermore, surgery was most often expressed by those labelled with a rotator cuff tear $(19.0 \%)$.

The findings of this study also align with a content analysis conducted by our group exploring public and patient perceptions of different labels for low back pain (O'Keeffe M, et al. Public and patient perceptions of diagnostic labels for low back pain: a content analysis. Under review). The study analysed free-text responses to two 
Table 4 All treatment themes from participants $(n=1308)$

\begin{tabular}{|c|c|}
\hline Treatment label & $\mathbf{N}(\%)$ \\
\hline Medication & $368(28.1)$ \\
\hline Rest & $300(22.9)$ \\
\hline Physiotherapy & $281(21.5)$ \\
\hline Exercise & $193(14.8)$ \\
\hline Exercise (intensity not specified) & $126(9.6)$ \\
\hline Light exercise & $67(5.1)$ \\
\hline Activity modification & $156(11.9)$ \\
\hline Surgery & $141(10.8)$ \\
\hline Heat & $117(8.9)$ \\
\hline Injection & $110(8.4)$ \\
\hline Cold & $86(6.6)$ \\
\hline Massage & $83(6.3)$ \\
\hline Unsure & $74(5.7)$ \\
\hline Investigations & $69(5.3)$ \\
\hline Doctor & $61(4.7)$ \\
\hline Topical treatments & $55(4.2)$ \\
\hline Normal movements & $54(4.1)$ \\
\hline No treatment & $48(3.7)$ \\
\hline Wait and see & $37(2.8)$ \\
\hline Irrelevant response & $35(2.7)$ \\
\hline Chiropractor & $29(2.2)$ \\
\hline Acupuncture & $22(1.7)$ \\
\hline Immobilisation & $16(1.2)$ \\
\hline Specialist & $15(1.1)$ \\
\hline Taping/bracing & $14(1.1)$ \\
\hline Hydrotherapy & $9(0.7)$ \\
\hline Natural or unknown therapies & $9(0.7)$ \\
\hline Compression & $7(0.5)$ \\
\hline Time off work & $7(0.5)$ \\
\hline Diet & $6(0.5)$ \\
\hline Electrotherapy & $5(0.4)$ \\
\hline Manipulation & $5(0.4)$ \\
\hline Prayer/hope/meditation & $5(0.4)$ \\
\hline Second opinion & $4(0.3)$ \\
\hline Elevation & $3(0.2)$ \\
\hline Ergonomics/posture & $3(0.2)$ \\
\hline Osteopathy & $3(0.2)$ \\
\hline Stay healthy & $3(0.2)$ \\
\hline Emergency department/hospital & $2(0.2)$ \\
\hline Cognitive behavioural therapy & $1(0.1)$ \\
\hline Good mattress & $1(0.1)$ \\
\hline Pain clinic & $1(0.1)$ \\
\hline
\end{tabular}

$\mathrm{N}$, number of participants; N/A, not applicable.

questions (identical to the questions asked in this study) which were collected in a six-arm, online randomised controlled experiment in participants with and without low back pain. Feelings of a poor prognosis were most common among participants labelled with a disc bulge, degeneration and arthritis, while feelings of a good prognosis were most common among those labelled with lumbar sprain, non-specific low back pain and an episode of low back pain. This is similar to our study where "poor prognosis' was often expressed by participants given structural labels for rotator cuff disease (eg, subacromial impingement syndrome) and 'good prognosis' was often expressed by those given non-specific labels (eg, episode of shoulder pain, shoulder sprain). Bursitis was the exception to this trend; a structural diagnosis that was rarely associated with 'poor prognosis' (2.7\%).

Perceived treatment needs for low back pain and rotator cuff disease appear to be similar. The top four treatments in the low back pain content analysis were exercise, medication, rest and physiotherapy (O'Keeffe M, et al. Public and patient perceptions of diagnostic labels for low back pain: a content analysis. Under review). In this study, the top four treatments for rotator cuff disease were medication, rest, physiotherapy and exercise. One difference is that exercise appears to be a more acceptable treatment for low back pain. For both low back pain and rotator cuff disease, labels appear to influence participants' perceived need for surgery. For low back pain, surgery was perceived as necessary among participants labelled with disc bulge, degeneration and arthritis more often than it was among those labelled with lumbar sprain, non-specific low back pain and an episode of low back pain. For rotator cuff disease, surgery was perceived as necessary among participants labelled with a rotator cuff tear, rotator-cuff-related shoulder pain and (to a lesser extent) subacromial pain syndrome more often than it was among those labelled with bursitis, shoulder sprain and episode of shoulder pain.

\section{Unanswered questions and future research}

Although some labels provoked negative feelings and perceived need for unnecessary care more than others, we do not know whether health professionals would find avoiding certain labels acceptable. Qualitative research is needed to fill this important knowledge gap. Our quantitative analysis also found only small differences in patients' perceived need for surgery and imaging between certain labels; these differences may not be clinically meaningful. Providing context and explanation for imaging findings (ie, that they are common in people without pain and in older people) and addressing misconceptions that are associated with certain labels might be more important for patients than avoiding certain labels. Testing these approaches should be a research priority.

\section{CONCLUSION}

Words or feelings evoked by certain labels for rotator cuff disease and perceived treatment needs may explain why some labels drive management preferences towards surgery and imaging more than others. Feelings of psychological distress and that the condition is serious and has a poor prognosis, and the need for treatment/ 
investigation and surgery were common among those labelled with a rotator cuff tear and subacromial impingement syndrome, but not among those labelled with bursitis. Interventions addressing misconceptions and perceived need for unnecessary care in patients given different labels for rotator cuff disease, and the clinicians who provide these labels, should be tested.

\section{Author affiliations}

${ }^{1}$ Institute for Musculoskeletal Health, School of Public Health, The University of Sydney and Sydney Local Health District, Camperdown, New South Wales, Australia ${ }^{2}$ Faculty of Health Sciences and Medicine, Institute for Evidence-Based Healthcare, Bond University, Gold Coast, Queensland, Australia

${ }^{3}$ School of Allied Health, Faculty of Education \& Health Sciences, University of Limerick, Limerick, Ireland

${ }^{4}$ Monash Department of Clinical Epidemiology, Cabrini Institute, Monash University, Malvern, Victoria, Australia

${ }^{5}$ Department of Epidemiology and Preventive Medicine, School of Public Health and Preventive Medicine, Monash University, Clayton, Victoria, Australia ${ }^{6}$ Ingham Institute for Applied Medical Research, South Western Sydney Clinical School, University of New South Wales, Sydney, New South Wales, Australia

Twitter Joshua R Zadro @zadro_josh, Mary 0'Keeffe @Mary0Keeffe007 and Giovanni E Ferreira @giovanni_ef

Contributors All authors critically revised the manuscript for important intellectual content and approved the final manuscript. Please find below a detailed description of the role of each author: JZ and ZAM: conception and design, analysis and interpretation of data, drafting and revision of the manuscript and final approval of the version to be published. MO'K, RH, IH, RB, CM and GF: conception and design, interpretation of data, drafting and revision of the manuscript and final approval of the version to be published.The corresponding author (JZ) attests that all listed authors meet authorship criteria and that no others meeting the criteria have been omitted. As guarantor, JZ accepts responsibiltiy for the overall content and conduct of the study, had access to the data, and controlled the decision to publish. JZ acts as a gaurantor.

Funding This study was funded by a National Health and Medical Research Council (NHMRC) Programme Grant (Wiser Healthcare: APP1113532).

Competing interests None declared.

Patient consent for publication Not required.

Ethics approval This study involves human participants and was approved by the University of Sydney Human Research Ethics Committee (reference number: 2020/159). Participants gave informed consent to participate in the study before taking part.

Provenance and peer review Not commissioned; externally peer reviewed.

Data availability statement Data are available upon reasonable request.

Supplemental material This content has been supplied by the author(s). It has not been vetted by BMJ Publishing Group Limited (BMJ) and may not have been peer-reviewed. Any opinions or recommendations discussed are solely those of the author(s) and are not endorsed by BMJ. BMJ disclaims all liability and responsibility arising from any reliance placed on the content. Where the content includes any translated material, BMJ does not warrant the accuracy and reliability of the translations (including but not limited to local regulations, clinical guidelines, terminology, drug names and drug dosages), and is not responsible for any error and/or omissions arising from translation and adaptation or otherwise.

Open access This is an open access article distributed in accordance with the Creative Commons Attribution Non Commercial (CC BY-NC 4.0) license, which permits others to distribute, remix, adapt, build upon this work non-commercially, and license their derivative works on different terms, provided the original work is properly cited, appropriate credit is given, any changes made indicated, and the use is non-commercial. See: http://creativecommons.org/licenses/by-nc/4.0/.

ORCID iDs

Joshua R Zadro http://orcid.org/0000-0001-8981-2125

Zoe A Michaleff http://orcid.org/0000-0002-0360-4956

Mary 0'Keeffe http://orcid.org/0000-0001-7104-9248

Giovanni E Ferreira http://orcid.org/0000-0002-8534-195X
Romi Haas http://orcid.org/0000-0001-9100-5509

\section{REFERENCES}

1 Rekola KE, Keinänen-Kiukaanniemi S, Takala J. Use of primary health services in sparsely populated country districts by patients with musculoskeletal symptoms: consultations with a physician. $J$ Epidemiol Community Health 1993;47:153-7.

2 Luime JJ, Koes BW, Hendriksen IJM, et al. Prevalence and incidence of shoulder pain in the general population; a systematic review. Scand J Rheumatol 2004;33:73-81.

3 Ostör AJK, Richards CA, Prevost AT, et al. Diagnosis and relation to general health of shoulder disorders presenting to primary care. Rheumatology 2005;44:800-5.

4 Whittle S, Buchbinder R. In the clinic. rotator cuff disease. Ann Intern Med 2015;162:ITC1-15.

5 Hegedus EJ, Goode AP, Cook CE, et al. Which physical examination tests provide clinicians with the most value when examining the shoulder? update of a systematic review with meta-analysis of individual tests. Br J Sports Med 2012;46:964-78.

6 Gismervik Sigmund $\varnothing$, Drogset JO, Granviken F, et al. Physical examination tests of the shoulder: a systematic review and metaanalysis of diagnostic test performance. BMC Musculoskelet Disord 2017:18:41.

7 Teunis T, Lubberts B, Reilly BT, et al. A systematic review and pooled analysis of the prevalence of rotator cuff disease with increasing age. J Shoulder Elbow Surg 2014;23:1913-21.

8 Schwartzberg R, Reuss BL, Burkhart BG, et al. High prevalence of superior Labral tears diagnosed by MRI in middle-aged patients with asymptomatic shoulders. Orthop J Sports Med 2016;4:232596711562321.

9 Girish G, Lobo LG, Jacobson JA, et al. Ultrasound of the shoulder: asymptomatic findings in men. AJR Am J Roentgenol 2011;197:W713-9.

10 Tran G, Cowling P, Smith T, et al. What Imaging-Detected pathologies are associated with shoulder symptoms and their persistence? A systematic literature review. Arthritis Care Res 2018;70:1169-84.

11 Guffey JS, Barymon D, Doerflein C, et al. Degenerative changes in asymptomatic subjects: a descriptive study examining the supraspinatus using musculoskeletal sonography in a young population. J Allied Health 2018;47:152-6.

12 Cools AM, Michener LA. Shoulder pain: can one label satisfy everyone and everything? Br J Sports Med 2017;51:416-7.

13 Nickel B, Barratt A, Copp T, et al. Words do matter: a systematic review on how different terminology for the same condition influences management preferences. BMJ Open 2017;7:e014129.

14 Zadro JR, O'Keeffe M, Ferreira GE. Diagnostic labels for rotator cuff disease can increase people's perceived need for shoulder surgery: an online randomized controlled trial. J Orthop Sports Phys Ther 2021;51:401-11.

15 Medicare item reports 2000/2001 to 2018/19. Available: http:// medicarestatistics.humanservices.gov.au/statistics/mbs_item.jsp [Accessed 15 Sep 2020].

16 Judge A, Murphy RJ, Maxwell R, et al. Temporal trends and geographical variation in the use of subacromial decompression and rotator cuff repair of the shoulder in England. Bone Joint $J$ 2014;96B:70-4.

17 Paloneva J, Lepola V, Äärimaa V, et al. Increasing incidence of rotator cuff repairs--A nationwide registry study in Finland. BMC Musculoskelet Disord 2015;16:189.

18 Zhang AL, Montgomery SR, Ngo SS, et al. Analysis of rotator cuff repair trends in a large private insurance population. Arthroscopy 2013;29:623-9.

19 Karjalainen TV, Jain NB, Page CM, et al. Subacromial decompression surgery for rotator cuff disease. Cochrane Database Syst Rev 2019;1:CD005619.

20 Karjalainen TV, Jain NB, Heikkinen J, et al. Surgery for rotator cuff tears. Cochrane Database Syst Rev 2019;12:CD013502.

21 Buchbinder R, Staples MP, Shanahan EM, et al. General practitioner management of shoulder pain in comparison with rheumatologist expectation of care and best evidence: an Australian national survey. PLoS One 2013;8:e61243.

22 Artus M, van der Windt DA, Afolabi EK, et al. Management of shoulder pain by UK general practitioners (GPs): a national survey. BMJ Open 2017;7:e015711.

23 Qualtrics. ESOMAR 28. 28 questions to help research buyers of online samples, 2014. Available: https://success.qualtrics.com/rs/ qualtrics/images/ESOMAR\%2028\%202014.pdf [Accessed 22 Jun 2020]. 
24 Weber RP. Content analysis. 2nd ed. Thousand Oaks, California: Sage, 1990: 117-24.

25 Landis JR, Koch GG. The measurement of observer agreement for categorical data. Biometrics 1977;33:159-74.

26 Copp T, McCaffery K, Azizi L, et al. Influence of the disease label 'polycystic ovary syndrome' on intention to have an ultrasound and psychosocial outcomes: a randomised online study in young women. Hum Reprod 2017;32:876-84.

27 McCaffery K, Nickel B, Moynihan R, et al. How different terminology for ductal carcinoma in situ impacts women's concern and treatment preferences: a randomised comparison within a national community survey. BMJ Open 2015;5:e008094.

28 Scherer LD, Finan C, Simancek D, et al. Effect of "Pink Eye" Label on Parents' Intent to Use Antibiotics and Perceived Contagiousness. Clin Pediatr 2016;55:543-8.
29 Scherer LD, Zikmund-Fisher BJ, Fagerlin A, et al. Influence of "GERD" label on parents' decision to medicate infants. Pediatrics 2013;131:839-45.

30 Cadogan A, Laslett M, Hing WA, et al. A prospective study of shoulder pain in primary care: prevalence of imaged pathology and response to guided diagnostic blocks. BMC Musculoskelet Disord 2011;12:119.

31 Naunton J, Harrison C, Britt H, et al. General practice management of rotator cuff related shoulder pain: a reliance on ultrasound and injection guided care. PLoS One 2020;15:e0227688.

32 Page MJ, Green S, McBain B. Manual therapy and exercise for rotator cuff disease. Cochrane Database Syst Rev 2016;6:CD012224.

33 Page MJ, Green S, Mrocki MA, et al. Electrotherapy modalities for rotator cuff disease. Cochrane Database Syst Rev 2016;6:CD012225.

34 Cuff $A$, Littlewood C. Subacromial impingement syndrome What does this mean to and for the patient? A qualitative study. Musculoskelet Sci Pract 2018;33:24-8. 